\title{
Integrating Energy System Models in Life Cycle Management
}

\author{
Miguel F. Astudillo, Kathleen Vaillancourt, Pierre-Olivier Pineau \\ and Ben Amor
}

\begin{abstract}
The energy supply chain is the backbone of industrialised societies, but it is also one of the leading causes of global environmental burden. Life cycle management (LCM) and life cycle assessment (LCA) are increasingly being used in combination with energy system optimisation models (ESOM) to better represent the energy sector and its dynamics, and facilitate better decision-making. The integration of ESOM and LCA can enable powerful analyses, but not without difficulties. In this chapter, we review studies linking a well-known bottom-up ESOM (TIMES) with LCA databases and identify the principal challenges and how they have been addressed. One of the main integration challenges is the identification of equivalent processes between life cycle inventories and ESOM databases: the mapping problem. Other concomitant issues such as double counting and parameter consistency have been identified and are also investigated.
\end{abstract}

\section{Introduction}

The economic growth observed in the last century has been heavily correlated with a sharp rise in energy use, improving living conditions for many, but also resulting in large environmental damage [1]. For instance, the energy sector is responsible for nearly two-thirds of global greenhouse gas emissions [2]. Therefore, there is an urgent need to transform the energy supply chain, decarbonising electricity supply

\footnotetext{
M. F. Astudillo $(\bowtie) \cdot$ B. Amor $(\square)$

Department of Civil Engineering, Université de Sherbrooke,

LIRIDE, Sherbrooke, Canada

e-mail: miguel@astudillo.com

B. Amor

e-mail: ben.amor@usherbrooke.ca

K. Vaillancourt

Esmia Consultants, Montreal, Canada

P.-O. Pineau

HEC Montreal, Chair in Energy Sector Management, Montreal, Canada

(C) The Author(s) 2018

E. Benetto et al. (eds.), Designing Sustainable Technologies,

Products and Policies, https://doi.org/10.1007/978-3-319-66981-6_28
} 
and electrifying services traditionally reliant on fossil fuels [2]. Many stakeholders have a role in this transition, from businesses to governments and consumers. Stakeholders need tools to understand how the energy system is likely to evolve and how it may react to various decisions made within the system.

In this journey, Life Cycle Management (LCM) can help to prevent burden shifting, but using it alone ignores the various energy dynamics. The use of energy system optimisation models (ESOM) together with life cycle thinking has the potential to underpin comprehensive understanding of the energy supply chain and its influence on sustainable production. There is a small but increasing number of studies combining life cycle assessment (LCA) and ESOM [3-12], ESOM best practices start to include LCM practices, such as goal and scope definition or the use of data quality indicators as a way to quantify epistemic uncertainty (i.e. the uncertainty associated with data quality) [13]. However, combining both models is not a simple task. In this chapter, we cover the challenges identified in the integration of ESOM and LCA, as well as existing approaches to address them and their limitations. For brevity, we focus on inventory level and do not cover impact assessment issues. Details of the criteria used to select articles are detailed in Sect. 1.3.

\subsection{Energy System Models: Origin and Strengths}

Energy infrastructure requires substantial investments and governments have used mathematical models for a long time to support policy analysis. The use of mathematical models can help understand the complex interactions that occur in the energy system, formalising the scattered knowledge about its dynamics [14]. Models of the energy sector grew in importance in the aftermath of the oil crisis of the 1970s. During that period the International Energy Agency (IEA) was founded and started developing its ESOM. Broadly speaking, energy models follow two different paradigms, they either provide scenarios of how the system could evolve from a normative standpoint (optimisation models), or they attempt to forecast how the system is likely to change (simulation models) [14]. Optimisation models are better suited to analyse long-term scenarios [15] and are therefore consistent with the common long-term temporal scope of LCA studies. This chapter focuses on bottom-up technology rich models, in particular the MARKAL/TIMES (The Integrated Markal Efom System) optimisation model generator developed by the IEA. TIMES is possibly the most widely used general purpose ESM [7, 14]. Alternative models following a similar structure such as TEMOA [16] or OSeMOSYS [17] are also considered.

TIMES models are based on cost minimisation and provide consistent possible evolutions of the energy system under a set of user-defined constraints. These models provide insights to businesses and policymakers, as they allow exploring potential interactions which are difficult to foresee without a formal mathematical framework. TIMES models are "bottom-up" models, with often thousands of 
technologies competing to provide a given level of demand for energy services. The solution of the optimisation problem provides potentially useful results, such as capacity additions, activity levels or material and emissions flows for each technology. TIMES models use simplifying assumptions, such as perfect competition. Perfectly competitive markets maximise the total surplus, which is an indicator of social welfare [15]. Thus, although real situations deviate from perfectly competitive markets, the solutions can be used as a benchmark. Deviations from perfect competition conditions can be studied through specific constraints such as pre-defined market-shares or myopic foresight [13, 15, 18]. In contrast with general-equilibrium models, TIMES models assume partial equilibrium, which means that sectors outside the system's boundary are assumed not to be affected by changes in the system. For instance, prices of imports and exports outside the boundaries of the system are exogenously defined and not determined by the model.

\subsection{Advantages of Integrating ESOM and LCA}

The advantages can be seen as an improvement in data quality aspects [19, 20]. TIMES models tend to have a relatively limited scope for assessing environmental burden, often only tracking primary pollutants from operating energy-related infrastructure [7, 18]. Most of them ignore up-stream emissions associated with imports [8] or consumption of resources linked to energy use, such as freshwater (of importance for the growing literature on the so-called water-energy nexus [21, 22]). Moreover, they lack the detailed impact assessment methodologies used in LCM. The absence of a comprehensive environmental assessment can result in burden shifting and fail to identify potential co-benefits of environmental policies. Life cycle thinking has been instrumental in addressing burden-shifting in the energy sector [23]. For example, it was through LCA studies that the environmental impact of biofuels was better understood [23].

TIMES models are also extremely useful for advanced life cycle studies, both for consequential and attributional approaches. TIMES explicitly model the future changes in the energy system, one of the major limitations of LCA [22]. The integration improves the temporal and technological representativeness, completeness and precision of inventories. TIMES also integrates economic considerations, which are fundamental in decision-making [19].

\subsection{Literature Review}

The integration challenges identified in this book chapter stem from our efforts linking the North American TIMES Energy Model (NATEM) with life cycle inventories (LCIs) [24, 25] and reading of associated literature. The existing approaches to address these challenges are based on a literature review. To identify 
potential articles, we used the search terms "LCA", "life cycle assessment", in combination with one of the following keywords: MARKAL, "TIMES model", OSeMOSYS, TEMOA, ESOM in the search engine Web of Science, covering publications of the last ten years. The keyword "TIMES" is too generic to be used as a meaningful filter. However, most of the publications mention the keyword MARKAL, the TIMES predecessor. To complete the review, we revised the annual summaries of the IEA Energy Technology Systems Analysis Program (ETSAP), covering publications from 2005 until 2013 [26]. ETSAP's reviews include over 250 references to articles using TIMES models in peer-reviewed journals. Studies deriving life cycle emissions from environmentally extended input-output (EEIO) data are included, despite having a different level of technological detail [8-10]. Only works published in peer-reviewed journals were considered. Studies that used LCA data for comparative purposes but did not attempt to integrate inventories (e.g. [27, 28]) or that had unclear methodology with unreachable authors [29] are not included in the review. Overall, ten articles are included in our analysis (Table 1). We note that prospective LCA of energy systems has also been done with other model paradigms such as general equilibrium models or power models [19]. However, linking such models entails different problems and is out of the scope of this chapter.

\section{LCA-TIMES Integration Challenges}

In TIMES models the energy supply chain is defined as a set of energy resources, conversion technologies and end-use demands connected by energy commodities in what is called the reference energy system (RES). The RES provides a complete

Table 1 Scope and number of technologies mapped in studies integrating TIMES models and LCA

\begin{tabular}{l|l|l|l|l}
\hline Sectors & $\begin{array}{l}\text { No of tech. } \\
\text { mapped }\end{array}$ & Scope & Database & Ref. \\
\hline Norwegian electricity sector & 9 & Attributional & ecoinvent 3 & {$[3]$} \\
\hline US electricity sector & 9 & Attributional & $\begin{array}{l}\text { US LCI and } \\
\text { ecoinvent } 2.2\end{array}$ & {$[4]$} \\
\hline $\begin{array}{l}\text { Multisector (end-uses) and } \\
\text { electricity sector (Switzerland) }\end{array}$ & 43 & Attributional & ecoinvent 2.2 & {$[5]$} \\
\hline Electricity and oil mining sector & 7 & Attributional & ecoinvent 1.1 & {$[7]$} \\
\hline Multisector & 192 & Consequential & ecoinvent 2.2 & {$[6]$} \\
\hline Spanish electricity sector & 26 & Consequential & ecoinvent 3 & {$[12]$} \\
\hline UK energy supply & 250 & Not stated & UK EE-MRIO & $\begin{array}{l}{[8,} \\
9]\end{array}$ \\
\hline EU electricity sector & 146 & Not stated & $\begin{array}{l}\text { Exiobase and } \\
\text { ecoinvent }\end{array}$ & {$[10]$} \\
\hline French biofuel sector & 35 & Not stated & mixed & {$[11]$} \\
\hline
\end{tabular}


description of the system boundaries and the level of technological detail of a model [30]. The RES is the equivalent to the product system in LCA [20]. The level of technological detail can be similar to process-based LCI databases. Thus, similar descriptions of the energy supply chain - from resource extraction to final use - can be found in both models. Linking ESM and LCI may seem straightforward, as both models share a similar structure, but these models are conceived to be used independently, and overlapping features can easily result in problems such as double counting [5, 6] or incomplete inventories. Faced with redundant information, the modellers need to choose which information prevails. The methodological choices may involve a trade-off between data quality aspects [19] which should be considered in the goal and scope definition.

Linking implies associating elements of the two models. We will refer to the problem of associating elements of two different models as the "mapping problem". Several issues complicate the mapping problem. First, TIMES models often include thousands of technologies, making a one-to-one linking between LCI and TIMES processes almost infeasible. There are no general name conventions or standard codes that can be used to automate the linking, which still heavily relies on manual identification. Second, both models can track the same emissions (e.g. greenhouse gases (GHG)), and some linkages between processes are not explicitly modelled in TIMES (e.g. cement production and infrastructure development). Adding LCI in the model can easily result in double counting [5]. Third, consistently introducing life-cycle emissions in the optimisation problem often requires a one-to-one mapping of processes in TIMES and LCIs. For example, emissions from end-of-life treatment could be included in TIMES, but these are potentially different for each process. In most of the cases, a one-to-one mapping would be excessively time-consuming. Fourth, key parameters of processes such as efficiency or emission factors may differ between models, which can result in inconsistencies. Finally, if multifunctional processes are within the system boundary, the allocation should be avoided using system expansion [20]. However, this is hardly discussed in the literature.

\section{Existing Approaches to Address the Integration Challenges}

\subsection{Mapping TIMES-LCA Processes}

The "too many processes" issue preventing a one-to-one mapping is one of the most complicated integration problems. This issue has been addressed using two simplifications: limiting the scope of the assessment to specific parts of the energy supply chain and representing sections of the supply chain by their aggregated LCI or LCA indicator. 
The integration efforts reviewed used multisector TIMES models, but most of the studies limit their scope to attributional studies of the electricity sector (Table 1) and do a partial integration. Several studies use market mixes from TIMES for prospective assessments, improving temporal representativeness [3, 4, 12], while others integrate life cycle emissions in TIMES models [7-11]. Limiting the boundaries to a particular sector reduces the number of technologies that need to be mapped, but it could result in a loss of completeness, questioning the suitability of the system boundary. For example, Ref. [4] used multisector MARKAL model to update a prospective electricity mix in the US for different scenarios such as cap and trade or $\mathrm{CO}_{2}$ taxes. However, such policies affect more than just the electricity sector, and induced changes in other sectors of the model should be considered to make a fair comparison of different scenarios. Refs. [7-11] added life cycle emissions to several processes of a MARKAL/TIMES model to internalise environmental emissions. It was a first step towards the integration of externalities, but incomplete mapping may be problematic as it may induce a bias against the mapped technologies (see Sect. 3.3). Reference [5] improved completeness, assigning life-cycle impact scores to all end-uses of all sectors. In this case, there is a wider range of processes that deliver the energy services (heat, transportation, etc.), raising the number of equivalent processes required (Table 1). The study used end-use technology mixes and energy demands from TIMES. However, the technology mixes and efficiencies for "non-end-use" processes (such as electricity generation) were selectively updated. The authors recommended using a more consistent approach in future research [5]. Indeed, upstream processes may also change over time or between scenarios (e.g. switch from conventional to unconventional gas or feedstock from biofuels). These changes should be identified in a systematic manner.

The approach of limiting the boundaries to a particular sector is more difficult to justify in consequential studies since all the processes that are expected to change should be included [19, 24]. Changes can be induced by market or policy effects. Our experiments using a TIMES model of a relatively small region (Quebec, Canada) indicate that a large proportion of the processes change their output to some extent [24]. The best example found of a consequential study using TIMES and LCA was an analysis of the effects of introducing biodiesel from biomass in France [6]. In this case, all technologies in the TIMES model were mapped (192). This approach produced a complete mapping, but it may be unfeasible with larger TIMES models, which can easily contain thousands of technologies.

We have recently proposed to use a cut-off criterion, that is, to exclude a percentage of the material and energy flows based on their contribution to an indicator measured in TIMES (e.g. $\mathrm{CO}_{2}$ eq emissions) [24]. The cut-off can help to discern the most relevant changes, reducing exponentially the number of processes that need to be mapped [24]. Nonetheless, it introduces some other problems, such as the possibility of omitting processes with high impacts in other areas of concern but low $\mathrm{CO}_{2}$ eq emissions. 


\subsection{Double Counting}

Double counting problem is hardly discussed in the literature of TIMES-LCA linking [5]. Part of the energy and emissions considered in TIMES models is used to deliver intermediate products that are already accounted in LCI, resulting in double counting $[5,6]$. For example, the output of the cement sector is typically considered independent of other demands in TIMES models but will be used to build the infrastructure that is already included in LCIs. As pointed by Ref. [6], this can be mitigated by presenting relative results between scenarios, where double counting effects cancel out, to some extent. This limitation is not exclusive of TIMES models. A recent review of integrated assessment models stated that most of them miss linkages related to infrastructure and ignore material cycles, which are the fundamental characteristics of the life cycle perspective [22]. Constructing more "circular" RES in TIMES models is challenging, as the models need to be calibrated using national statistics, and these do not necessarily have a high level of detail of material flows leaving each sector. Studies linking TIMES with EEIO data have more thoughtfully addressed double counting, erasing manually repeated areas of the inventory [8-10]. Reference [10] used fixed input-output coefficients to adjust the exogenously defined demands (e.g. the steel demand from energy technologies is used to adjust the energy demand of steel production). Ideally, these demand corrections would be calculated endogenously by the TIMES model, but that would require substantial additional linking of processes.

\subsection{Integrating Life Cycle Emissions in the Optimisation Problem}

Several of the reviewed publications integrated LCA data into the optimisation algorithm, but only for some parts of the energy system [3,7-11], with the risk of introducing a bias. A consistent integration of life-cycle emissions into the optimisation problem is challenging, as it will bias the assessment towards sectors where accounting of emissions is less complete. Reference [3] noted that imposing limits on LCA scores for electricity generation greatly affected trade balances against local production, as trade processes did not have emissions associated. Consistently including emissions for all processes in a TIMES model (e.g. end-of-life burdens) would require a one-to-one mapping, which is extremely time-consuming in large TIMES models. Alternatively, large TIMES models can include emissions if it is for a limited number of processes. For example, a model dealing with operating GHG emissions could include emissions from gas distribution or refrigerant leaks or electricity imports (e.g. [25]) without losing consistency. Ultimately, TIMES results should be interpreted taking into account potential inconsistencies and lack of completeness of the inventories. References $[8,10]$ are 
good examples, as they provide guidance on how to interpret results and what kind of conclusions could not be drawn.

\subsection{Technological Representativeness}

TIMES inventories represent future supply chains, while most of the LCI data are from current supply chains. Parameters such as efficiency, capacity factors or emission factors of the same technology may therefore differ. Unless a harmonisation step is introduced, the integration could lead to inconsistencies. The level of consistency in the different integration is difficult to evaluate because, with some exceptions (e.g. [5, 8]) it is not well documented and rarely discussed. Studies using EEIO data acknowledge that sectoral aggregation is an additional problem, as sectors with different emission intensities can be grouped together, eroding data representativeness [8]. References [3,30] suggested learning from the experiences linking bottom-up and general equilibrium models. Some of the concepts developed during other integration efforts can be applied to the integration of TIMES models and LCA databases. For example, the introduction of common measurement points (i.e. points where both models have the same result) would be useful to formalise the linking approach.

\subsection{Dealing with Multifunctional Processes}

Multifunctional processes should be handled in a way that is consistent with the scope of the analysis and if possible, avoiding the allocation using system expansion [20]. However, except Ref. [6], studies do not specify how allocation has been conducted when it could not be avoided (e.g. one of the outputs being outside the system boundary).

\section{Discussion and Conclusions}

The TIMES-LCA integration is clearly in expansion, with several recent publications on the topic. Integration can range from a very simple level (e.g. identification of future average or marginal technologies in a particular energy market), to more detailed ones, capturing market and policy interactions and transformations in the entire energy supply chain. More comprehensive approaches also imply a substantial additional effort, particularly solving the mapping of processes between the two bottom-up models.

To date, the existing literature has focused on attributional studies of electricity generation, although some multisector and consequential studies exist. Limiting the 
scope to part of the system may miss important changes outside the chosen system boundaries. The potential lack of completeness needs to be considered in the definition of the goal and scope. The truncation of the system boundary is especially unwarranted for consequential studies, where limiting the scope to specific sectors would result in an incomplete inventory.

TIMES and LCA often have overlapping representations of the supply chain, and modellers have to choose which data prevail, substituting parts of the TIMES representation by LCA counterparts. Direct substitution entails the risk of missing important changes across the supply chain. Therefore, the need for systematic approaches to prioritise which LCI data should be updated. The ordering of processes and application of a cut-off based on a criterion such as $\mathrm{CO}_{2}$ eq emissions can help to both identify relevant changes and reduce the number of processes to be mapped.

Consistent linking requires also updating parameters such as efficiency and emission factors. Integration efforts outside the LCA field suggested already in 1996 to use common measurement points, unambiguous measurement points where the two models should yield identical results [30]. The formalisation of these points implies a harmonisation of parameters, and the assessment of the extent by which both models measure the same phenomena and the same future [30]. The author also pointed out the need to share a common formalised language between models [30]. The specification of such conceptualisation is called ontology, a field of growing interest in industrial ecology and recently discussed in the LCM conference [31]. The need for more traceable and transparent workflows that go beyond the common reporting on scientific articles was also stressed [31]. We agree, as articles often don't offer sufficient explanation to understand the details of how the linking was done.

The process of linking models goes beyond solving the implementation problem [30]. It is also an opportunity to learn about the system and the implications of different perspectives, which are essential to interpret results. LCA modellers should consequently keep in mind the underlying assumptions and values of ESOM.

\section{References}

1. Smil V, World history and energy. Encycl Energy 2004;6:549-61.

2. IEA, Energy, climate change and environment, 2016 insights 2016. http://www.iea.org/ publications/freepublications/publication/ECCE2016.pdf (accessed September 23, 2017).

3. García-Gusano D, Iribarren D, Martín-Gamboa M, Dufour J, Espegren K, Lind A, Integration of life-cycle indicators into energy optimisation models: The case study of power generation in Norway. J Clean Prod 2016;112:2693-6.

4. Choi J-K, Friley P, Alfstad T, Implications of energy policy on a product system's dynamic life-cycle environmental impact: Survey and model. Renew Sustain Energy Rev 2012;16: $4744-52$. 
5. Volkart K, Weidmann N, Bauer C, Hirschberg S, Multi-criteria decision analysis of energy system transformation pathways: A case study for Switzerland. Energy Policy 2017;106: 155-68.

6. Menten F.M, Tchung-ming S, Lorne D, Bouvart F, Lessons from the use of a long-term energy model for consequential life cycle assessment: the BTL case. Renew Sustain Energy Rev 2015;43:942-60.

7. Pietrapertosa F, Cosmi C, Macchiato M, Salvia M, Cuomo V, Life Cycle Assessment, ExternE and Comprehensive Analysis for an integrated evaluation of the environmental impact of anthropogenic activities. Renew Sustain Energy Rev 2009;13:1039-48.

8. Daly H.E, Scott K, Strachan N, Barrett J, Indirect $\mathrm{CO}_{2}$ Emission Implications of Energy System Pathways: Linking IO and TIMES Models for the UK. Environ Sci Technol 2015;49:10701-9.

9. Scott K, Daly H, Barrett J, Strachan N, National climate policy implications of mitigating embodied energy system emissions. Clim Change 2016;136:325-38.

10. McDowall W, Solano Rodriguez B, Usubiaga A, Acosta Fernández J, Is the optimal decarbonization pathway influenced by indirect emissions? Incorporating indirect life-cycle carbon dioxide emissions into a European TIMES model. J Clean Prod 2018;170:260-8.

11. Hugues P, Assoumou E, Maizi N, Assessing GHG mitigation and associated cost of French biofuel sector: Insights from a TIMES model. Energy 2016;113:288-300.

12. García-Gusano D, Garraín D, Dufour J, Prospective life cycle assessment of the Spanish electricity production. Renew Sustain Energy Rev 2016;75:21-34.

13. DeCarolis J, Daly H, Dodds P, Keppo I, Li F, McDowall W, et al, Formalizing best practice for energy system optimization modelling. Appl Energy 2017;194:184-98.

14. Pfenninger S, Hawkes A, Keirstead J, Energy systems modeling for twenty-first century energy challenges. Renew Sustain Energy Rev 2014;33:74-86.

15. Loulou R, Remme U, Kanudia A, Lehtila A, Goldstein G, Documentation for the TIMES Model Part I. IEA Energy Technol Syst Anal Program 2005:1-78. https://iea-etsap.org/docs/ Documentation_for_the_TIMES_Model-Part-I_July-2016.pdf (accessed September 23, 2017).

16. Hunter K, Sreepathi S, DeCarolis J.F, Modeling for insight using Tools for Energy Model Optimization and Analysis (Temoa). Energy Econ 2013;40:339-49.

17. Howells M, Rogner H, Strachan N, Heaps C, Huntington H, Kypreos S, et al, OSeMOSYS: The Open Source Energy Modeling System. Energy Policy 2011;39:5850-70.

18. Glynn J, Fortes P, Krook-Riekkola A, Labriet M, Vielle M, Kypreos S, et al, Informing energy and climate policies using energy systems models. Springer International Publishing; 2015.

19. Astudillo M.F, Treyer K, Bauer C, Pineau P.O, Amor M Ben, Amor B, Life cycle inventories of electricity supply through the lens of data quality: exploring challenges and opportunities. Int J Life Cycle Assess 2016;3:374-86.

20. ISO, ISO 14044 Environmental management-Life cycle assessment-Requirements and guidelines. vol. 3. 2006.

21. Kapsarc, Energy Systems Modeling to Support Policy Making 2014. https://www.kapsarc. org/wp-content/uploads/2015/10/KS-1401-WB01B-Energy-Modeling-Workshop-PolicyBrief.pdf (accessed September 19, 2017).

22. Pauliuk S, Arvesen A, Stadler K, Hertwich E.G, Industrial ecology in integrated assessment models. Nat Clim Chang 2017;7:13-20.

23. Hellweg S, Milà i Canals L, Emerging approaches, challenges and opportunities in life cycle assessment. Science 2014;344:1109-13.

24. Astudillo M.F, Vaillancourt K, Pineau P, Amor B, Simplifying the integration of energy system models and LCA. Setac Brussels 2017, Brussels: 2017, p. 3-4. https://osf.io/cxzra (accessed September 19, 2017).

25. Astudillo M.F, Vaillancourt K, Pineau P.O, Amor B, Can the household sector reduce global warming mitigation costs? sensitivity to key parameters in a TIMES techno-economic energy model. Appl Energy 2017;205:486-98. 
26. ETSAP, Other. Annex Final Reports 2013. https://iea-etsap.org/index.php/applications/other (accessed September 19, 2017).

27. Frenette E, Bahn O, Vaillancourt K, Meat, Dairy and Climate Change: Assessing the Long-Term Mitigation Potential of Alternative Agri-Food Consumption Patterns in Canada. Environ Model Assess 2016.

28. Levasseur A, Bahn O, Beloin-Saint-Pierre D, Marinova M, Vaillancourt K, Assessing butanol from integrated forest biorefinery: A combined techno-economic and life cycle approach. Appl Energy 2017:1-13.

29. Tokimatsu K, Endo E, Murata A, Okajima K, Nomura N, An Integrated Assessment by Models for Energy Systems Analysis and Life-Cycle Assessment with a Case Study of Advanced Fossil-Fired Power Plants in China. Environ Model Assess 2015:291-305.

30. Wene C.O, Energy-economy analysis: Linking the macroeconomic and systems engineering approaches. Energy 1996;21:809-24.

31. Vandepaer L, Gibon T, 2018. The integration of energy scenarios into LCA: LCM 2017 Conference Workshop, Luxembourg, September 5, 2017. Int J Life Cycle Assess 23:970-977.

Open Access This chapter is licensed under the terms of the Creative Commons Attribution 4.0 International License (http://creativecommons.org/licenses/by/4.0/), which permits use, sharing, adaptation, distribution and reproduction in any medium or format, as long as you give appropriate credit to the original author(s) and the source, provide a link to the Creative Commons license and indicate if changes were made.

The images or other third party material in this chapter are included in the chapter's Creative Commons license, unless indicated otherwise in a credit line to the material. If material is not included in the chapter's Creative Commons license and your intended use is not permitted by statutory regulation or exceeds the permitted use, you will need to obtain permission directly from the copyright holder.

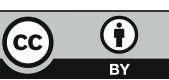

